\title{
Review: low-dose thiazides are the most effective first-line drugs for hypertension
}

Wright JM, Lee CH, Chambers GK. Systematic review of antihypertensive therapies: does the evidence assist in choosing a first-line drug? CMAJ 1999 Jul 13;161:25-32.

QUESTION: In patients with hypertension, which first-line drugs are effective for reducing death and cardiovascular events?

\section{Data sources}

Studies were identified by searching Medline (1966-97), the Cochrane Library (1998 issue 2), and references of previous meta-analyses (1980-97).

\section{Study selection}

Studies were selected if patients had systolic blood pressure $\geq 160 \mathrm{~mm} \mathrm{Hg}$ or diastolic blood pressure $\geq 90 \mathrm{~mm}$ $\mathrm{Hg}$; random allocation was used; a first-line antihypertensive drug was compared with another first-line drug or no treatment (including placebo); group baseline characteristics were reported; end points were defined; $\geq 1$-year of follow-up was reported; and $>70 \%$ of patients were receiving the study drug after 1 year. Studies were excluded if antihypertensive drugs were used for indications other than hypertension.

\section{Data extraction}

2 reviewers independently extracted data on patients, study duration, treatment, outcomes (death, stroke, coronary artery disease [CAD], and total cardiovascular events), and withdrawals because of adverse effects.

\section{Main results}

23 studies (50 853 patients) met the inclusion criteria. Sample sizes ranged from 87-17 354 patients. In metaanalyses of drug-drug comparisons, no differences existed in death, stroke, CAD, or total cardiovascular events. Fewer withdrawals because of adverse effects occurred with thiazides than with $\beta$-blockers and in 1 trial with a calcium-channel blocker than with an angiotensin-converting enzyme (ACE) inhibitor (table). In comparisons of drugs with no treatment, low-dose thiazides reduced death, and thiazides (all doses) and a calcium-channel blocker reduced stroke and total cardiovascular events; only low-dose thiazides reduced CAD (table).

\section{Conclusion}

In patients with hypertension, low-dose thiazides are effective for reducing death, stroke, and coronary artery disease.

\section{COMMENTARY}

Many large studies have shown that low-dose thiazide diuretics are efficacious and efficient in treating hypertension. Several national guidelines, including the US Joint National Committee on the Prevention, Detection, and Evaluation and Treatment of Hypertension, ${ }^{1}$ have recommended thiazides as first-line antihypertensive therapy. Yet in practice, use of thiazides lags far behind the newer antihypertensive drugs, even though the effectiveness of these has been less well shown.

Unfortunately, few direct comparisons have been done among different classes of antihypertensive drugs. Those comparisons that have been done were limited to 2 classes of drugs in any 1 study, usually between $\beta$-blockers and thiazides. A comparison of several classes of drugs is now under way in the Antihypertensive and Lipid Lowering Treatment to Prevent Heart Attack Trial (ALLHAT) study. ${ }^{2}$ It is designed to compare the mortality and cardiovascular outcomes of a relatively high-risk group of patients with hypertension treated with either a thiazide, a calciumchannel blocker, an ACE inhibitor, or an $\alpha$-blocker. This large study with 42451 patients is partially completed, and final results are expected in 2-3 years.

What should clinicians do until then? As concluded in this and other systematic reviews (using somewhat different methods), low-dose thiazides should be the first line of treatment for hypertension. Such treatment reduces not only risk for stroke but also other cardiovascular morbidity and mortality. Thiazides are inexpensive drugs with the strongest evidence for effectiveness from hypertension studies.

Mohammad G Saklayen, MD Wright State University, Centerville, Ohio, USA

1 Arch Intern Med 1997;157:2413-46.

2 Davis BR, Cutler JA, Gordon DJ, et al. Am J Hypertens 1996;9:342-60.
Sources of funding: British Columbia Ministry of Health and the University of British Columbia.

For correspondence: $\mathrm{Dr}$ JM Wright,

Department of

Pharmacology and

Therapeutics, 2176

Health Sciences Mall,

University of British

Columbia, Vancouver

British Columbia V6T

1Z3, Canada.FAX

604-822-0701.
Effectiveness of first-line antihypertensive drugs for hypertension at up to 10 years*

\begin{tabular}{|c|c|c|c|}
\hline Comparison & $\begin{array}{l}\text { Number of } \\
\text { studies }\end{array}$ & Outcomes & $\begin{array}{l}\text { Pooled RRR (95\% } \\
\text { CI) }\end{array}$ \\
\hline Thiazides $v \beta$-blockers & 5 & Withdrawals because of adverse effects & $31 \%(24$ to 37$)$ \\
\hline \multirow[t]{4}{*}{ Low-dose thiazides $v$ no treatment } & 5 & Death & $11 \%(1$ to 19$)$ \\
\hline & & Stroke & $34 \%(21$ to 44$)$ \\
\hline & & Coronary artery disease & $29 \%(16$ to 40$)$ \\
\hline & & Cardiovascular events & $32 \%(25$ to 38$)$ \\
\hline \multirow[t]{2}{*}{ High-dose thiazides $v$ no treatment } & 11 & Stroke & $53 \%$ (39 to 63$)$ \\
\hline & & Cardiovascular events & $28 \%$ (18 to 37$)$ \\
\hline \multirow[t]{3}{*}{ Calcium-channel blockers $v$ no treatment } & 1 & Stroke & $39 \%(13$ to 57$) \dagger$ \\
\hline & & Cardiovascular events & $39 \%(13$ to 43$) \dagger$ \\
\hline & & & $R R I(C l)$ \\
\hline ACE inhibitors $v$ calcium-channel blockers & 1 & Withdrawals because of adverse effects & $231 \%(119$ to 400$) \dagger$ \\
\hline
\end{tabular}

*ACE = angiotensin-converting enzyme. Other abbreviations defined in glossary. †Not pooled. 